Ophthalmologica

\title{
Corneal Curvature after Penetrating Keratoplasty before and after Suture Removal: A Comparison between Keratoconus and Fuchs' Dystrophy
}

\author{
Berthold Seitz $^{a} \quad$ Achim Langenbucher $^{a}$ Nora Szentmary $^{b}$ \\ Gottfried O.H. Naumann ${ }^{\text {a }}$ \\ a Department of Ophthalmology, University of Erlangen-Nürnberg, Erlangen, Germany; \\ ${ }^{\mathrm{b}}$ Department of Ophthalmology, Semmelweis University, Budapest, Hungary
}

\section{Key Words}

Fuchs' dystrophy · Keratoconus - Postkeratoplasty outcome $\cdot$ Visual acuity $\cdot$ Astigmatism $\cdot$ Central corneal power $\cdot$ Topographic regularity $\cdot$ Corneal curvature

\begin{abstract}
Purpose: To assess the differences concerning corneal curvature and visual acuity after penetrating keratoplasty (PKP) comparing keratoconus (KC) and Fuchs' dystrophy (FUCHS). Methods: Inclusion criteria for this prospective, comparative, interventional study were: (1) one surgeon, (2) central round nonmechanical excimer laser PKP without previous surgery, (3) FUCHS $(n=35)$ or KC $(n=52)$, (4) standardized graft size $(7.5-8.0 \mathrm{~mm})$ and technique, 16-bite double running cross-stitch suture. In $69 \%$ of FUCHS, a triple procedure was performed. The main outcome measures were: keratometric astigmatism, surface regularity index, surface asymmetry index, keratometric central corneal power and bestcorrected visual acuity before $(1.2 \pm 0.4$ years $)$ and after suture removal (1.8 \pm 0.6 years). Results: Astigmatism did not differ significantly between KC and FUCHS ( $p>0.1)$ before (3.3 dpt vs. $3.5 \mathrm{dpt}$ median) and after suture removal ( $2.5 \mathrm{dpt}$ vs. $3.0 \mathrm{dpt}$ ). Surface regularity index and surface asymmetry index were significantly higher in FUCHS than in $K C(p<0.001)$ at both time stages. Central power was significantly greater in KC than in FUCHS $(p<0.001)$ with sutures
\end{abstract}

in place. Due to a significant steepening in FUCHS and flattening in $\mathrm{KC}$, this difference was no longer present after suture removal. Visual acuity in $\mathrm{KC}$ exceeded that in FUCHS before $(0.68 \mathrm{vs.} 0.60)$ and even more after suture removal ( 0.86 vs. $0.60 ; p<0.001)$. Conclusions: In KC, keratometric astigmatism is not higher than in FUCHS after PKP. After suture removal, graft topography in KC and FUCHS may be expected to regularize and the excessive corneal flattening in FUCHS to normalize in the mid-term.

Copyright $\odot 2006$ S. Karger AG, Basel

\section{Introduction}

Keratoconus (KC) and Fuchs' dystrophy (FUCHS) are by far the leading indications for penetrating keratoplasty (PKP) in our departments. There is concern among corneal specialists that in $\mathrm{KC}$ the astigmatism might be higher and topographic regularity lower due to the potentially diseased irregular peripheral host corneal rim persisting after trephination [1].

In contrast to conventional mechanical trephination, nonmechanical corneal trephination avoids mechanical distortion due to radial and tangential forces during trephination, resulting in significantly less 'all-suturesout' astigmatism, higher regularity of the topography and better visual acuity $[2,3]$.

\section{KARGER}

Fax +4161306 1234

E-Mail karger@karger.ch

www.karger.com
(C) 2006 S. Karger AG, Basel

$0030-3755 / 06 / 2205-0302 \$ 23.50 / 0$

Accessible online at:

www.karger.com/oph
Prof. Dr. med. Berthold Seitz

Klinikum für Augenheilkunde, Universitätsklinikum des Saarlandes Kirrberger Strasse, Gebäude 22, DE-66421 Homburg/Saar (Germany) Tel. +496841 162 2388, Fax +496841 1622400

E-Mail berthold.seitz@uniklinikum-saarland.de 
Table 1. Results with all sutures in place after 88 penetrating keratoplasties

\begin{tabular}{lllllll}
\hline & $\begin{array}{l}\text { Astigmatism } \\
\mathrm{dpt}\end{array}$ & $\begin{array}{l}\text { Central power } \\
\mathrm{dpt}\end{array}$ & SRI & SAI & SEQ, dpt & $\begin{array}{l}\text { BCVA } \\
\text { (decimals/logMAR) }\end{array}$ \\
\hline KC (n=52) & $\begin{array}{l}3.6 \pm 1.9,3.3 \\
(0.5-8.5)\end{array}$ & $\begin{array}{l}42.9 \pm 2.5,43.3 \\
(36.0-47.0)\end{array}$ & $\begin{array}{l}1.26 \pm 0.61,1.12 \\
(0.45-3.23)\end{array}$ & $\begin{array}{l}1.16 \pm 0.98,0.81 \\
(0.22-4.30)\end{array}$ & $\begin{array}{l}-1.9 \pm 3.7,-2.0 \\
(-10.0-12.1)\end{array}$ & $\begin{array}{l}0.71 \pm 0.21,0.68 \\
(0.05-1.0) /-0.14, \\
-0.26(-1.3 \text { to } 0.0)\end{array}$ \\
\hline p value & n.s. & $<0.001$ & $<0.001$ & $<0.001$ & $<0.001$ & $<0.01$ \\
\hline FUCHS (n=35) & $\begin{array}{l}3.2 \pm 1.6,3.5 \\
(0.8-6.5)\end{array}$ & $\begin{array}{l}40.5 \pm 3.0,41.1 \\
(34.3-44.8)\end{array}$ & $\begin{array}{l}1.50 \pm 0.45,1.51 \\
(0.76-2.65)\end{array}$ & $\begin{array}{l}1.44 \pm 0.70,1.24 \\
(0.59-2.87)\end{array}$ & $\begin{array}{l}0.5 \pm 3.1,0.3 \\
(-4.5-9.5)\end{array}$ & $\begin{array}{l}0.55 \pm 0.15,0.60 \\
(0.3-0.9) /-0.25,-0.22 \\
(-0.52 \text { to }-0.04)\end{array}$ \\
\hline
\end{tabular}

SRI = Surface regularity index; SAI = surface asymmetry index; SEQ = spherical equivalent; BCVA = best spectacle-corrected visual acuity; n.s. = not significant. BCVA results in the logMAR scale are expressed as mean, median and range (in parentheses). All other results are expressed as mean $\pm \mathrm{SD}$, median and range (in parentheses).

The purpose of the present study was to assess the differences concerning astigmatism, topographic regularity, central corneal power and visual acuity after excimer laser PKP comparing KC and FUCHS before and after suture removal. The work was carried out at the Department of Ophthalmology of University of Erlangen-Nürnberg, Erlangen, Germany.

\section{Patients and Methods}

\section{Patients and Donor Details}

Inclusion criteria for this prospective, comparative, interventional study consisted of: (1) one surgeon, (2) primary central round nonmechanical excimer laser PKP without previous surgery, (3) FUCHS $(\mathrm{n}=35)$ or KC $(\mathrm{n}=52)$, (4) standardized graft size $(7.5-8.0 \mathrm{~mm})$ and technique, 16-bite double running crossstitch suture. Exclusion criteria were (1) maculopathy, (2) optic nerve atrophy, or (3) amblyopia. Mean age was $50.9 \pm 17.1$ years $(39.5 \pm 11.5$ years in $\mathrm{KC}, 67.8 \pm 7.1$ years in FUCHS). In $69 \%$ of FUCHS, simultaneous extracapsular cataract extraction and posterior chamber lens implantation (triple procedure) were performed.

\section{Trephination and Suturing Techniques}

Nonmechanical trephination was performed using the 193 nm excimer laser MEL60 ${ }^{\circledR}$ (Carl Zeiss Meditec, Jena, Germany) along metal masks with eight orientation teeth/notches. Donor trephination was achieved from the epithelial side in all eyes using corneoscleral buttons fixed in an artificial anterior chamber (Polytech, Rossdorf, Germany). After temporary fixation of the donor button in the recipient bed with 8 interrupted sutures, a permanent wound closure was ensured by a 16-bite double running diagonal cross-stitch suture (10-0 nylon). Further methodical details have been published elsewhere [3-5].

Corneal Curvature after Penetrating Keratoplasty

\section{Additional Lens Surgeries}

During a mean follow-up of $4.3 \pm 2.5$ years, 12 sequential cataract extractions $(13.7 \%)$ became necessary after an average of $2.2 \pm 1.7$ (1.1-7.4, median 1.6) years following PKP. They included 5 of $52 \mathrm{KC}$ eyes $(9.6 \%)$ due to steroid-induced posterior capsular opacification and 7 of 35 FUCHS eyes (20.0\%) due to progressive nuclear and cortical cataracts. Overall, $13 \mathrm{Nd}$ :YAG laser capsulotomies (11.2\%) had to be performed after an average of $2.3 \pm$ $1.2(0.3-4.6$, median 2.1$)$ years following triple procedures in FUCHS

\section{Methods and Main Outcome Measures}

Main outcome measures included: (1) keratometric astigmatism (Zeiss ophthalmometer), (2) central corneal power (= keratometric diopters), (3) surface regularity index (SRI), (4) surface asymmetry index (SAI) of the TMS-1 topographer, (5) best spectacle-corrected visual acuity, and (6) spherical equivalent (SEQ) - each before removal of the first suture $(1.2 \pm 0.4$ years $)$ and after removal of the second suture $(1.8 \pm 0.6$ years $)$, but before any additional surgery, such as phacoemulsification.

\section{Statistical Analysis}

For statistical analysis, SPSS/PC 9.0 (Windows NT) was used. Comparisons between groups or variables were performed using nonparametric tests (Mann-Whitney U test for unpaired samples, Wilcoxon test for paired samples). A p value $<0.05$ was considered statistically significant.

\section{Results}

Astigmatism did not differ significantly between $\mathrm{KC}$ and FUCHS ( $p>0.1$ ) - neither before ( 3.3 vs. 3.5 dpt median) nor after suture removal (2.5 vs. $3.0 \mathrm{dpt}$ ) (tables 1 and 2). After suture removal, keratometric astigmatism decreased in both groups. 
Table 2. Results with all sutures removed after 88 penetrating keratoplasties

\begin{tabular}{lllllll}
\hline & $\begin{array}{l}\text { Astigmatism } \\
\mathrm{dpt}\end{array}$ & $\begin{array}{l}\text { Central power } \\
\mathrm{dpt}\end{array}$ & SRI & SAI & SEQ, dpt & $\begin{array}{l}\text { BCVA } \\
\text { (decimals/logMAR) }\end{array}$ \\
\hline KC (n=52) & $\begin{array}{l}2.8 \pm 2.1,2.5 \\
(0.0-10.7)\end{array}$ & $\begin{array}{l}42.5 \pm 2.2,42.6 \\
(38.5-49.0)\end{array}$ & $\begin{array}{l}0.81 \pm 0.39,0.76 \\
(0.22-1.85)\end{array}$ & $\begin{array}{l}0.71 \pm 0.68,0.55 \\
(0.26-4.23)\end{array}$ & $\begin{array}{l}-1.9 \pm 3.1,-1.5 \\
(-10.0-4.9)\end{array}$ & $\begin{array}{l}0.75 \pm 0.28,0.86 \\
(0.01-1.20) /-0.12, \\
-0.06(-2.0-0.07)\end{array}$ \\
\hline p value & n.s. & n.s. & $<0.001$ & $<0.001$ & $<0.05$ & $<0.001$ \\
\hline FUCHS (n=35) & $\begin{array}{l}3.1 \pm 1.9,3.0 \\
(0.5-9.0)\end{array}$ & $\begin{array}{l}42.1 \pm 2.8,42.4 \\
(36.3-45.8)\end{array}$ & $\begin{array}{l}1.07 \pm 0.51,0.99 \\
(0.39-2.40)\end{array}$ & $\begin{array}{l}1.20 \pm 0.88,0.90 \\
(0.39-3.70)\end{array}$ & $\begin{array}{l}-0.6 \pm 3.2,-0.8 \\
(-7.5-6.4)\end{array}$ & $\begin{array}{l}0.67 \pm 0.19,0.60 \\
(0.3-1.0) /-0.17, \\
-0.22(-0.52-0.0)\end{array}$ \\
\hline
\end{tabular}

BCVA results in the logMAR scale are expressed as mean, median and range (in parentheses). All other results are expressed as mean $\pm \mathrm{SD}$, median and range (in parentheses).

The central power was significantly flatter in FUCHS $(41.1 \mathrm{dpt})$ than in $\mathrm{KC}(43.3 \mathrm{dpt})(\mathrm{p}<0.001)$ as long as the sutures were in place. Due to a significant steepening in FUCHS ( $\mathrm{p}<0.01)$ and a flattening in KC this difference was no longer present after suture removal.

SEQ in KC was significantly more myopic than in FUCHS before $(\mathrm{p}<0.001)$ suture removal. Due to a significant myopic shift in FUCHS $(\mathrm{p}<0.01)$ this difference between FUCHS and KC shrunk with all sutures out $(\mathrm{p}<0.05)$.

Before (1.53 vs. 1.18) and after suture removal (1.08 vs. $0.78)$ SRI was significantly higher in FUCHS than in KC $(\mathrm{p}<0.001)$. Likewise, SAI was higher in FUCHS than in $\mathrm{KC}$ before (1.25 vs. 0.72$)$ and after suture removal (0.91 vs. $0.58 ; \mathrm{p}<0.001)$. However, in KC and FUCHS the topographic irregularities became significantly less after suture removal $(\mathrm{p}<0.001)$.

Visual acuity in KC exceeded that in FUCHS before $(0.68$ vs. 0.60$)$ and even more so after suture removal ( 0.86 vs. $0.60 ; p<0.001)$. Median visual acuity increased only in $\mathrm{KC}$ after suture removal.

\section{Discussion}

Many studies support substantial and rapid improvement in visual acuity after PKP for KC [6-9], although up to $47 \%$ of eyes may require contact lenses for optimal vision [10]. However, little is known about the functional results after PKP for FUCHS [11]. The present study supports our clinical impression that the visual acuity after PKP is more favorable in KC than in FUCHS. By nature, this study cannot have a randomized controlled design since FUCHS patients are older, and older patients may have more tear film abnormalities, visual acuity tends to drop with age, and older patients tend to develop cataracts that are often extracted simultaneously [12]. An additional factor is that patients with $\mathrm{KC}$ have larger corneas which may require larger corneal grafts. However, the fact that a homogeneous $0.1-\mathrm{mm}$ graft oversize (donor trephination from the epithelial side) and a standardized suture technique were performed by only one experienced surgeon adds strength to the statistical confirmation of our findings in the present study in comparing the properties of both diseases during mid-term follow-up.

Most interestingly, keratometric astigmatism did not differ significantly between FUCHS and KC. This was true before and also after suture removal. In a previous study, it was shown that with increasing diameter of the graft, neither all-sutures-in, nor all-sutures-out keratometric astigmatism differs significantly following excimer laser trephination [13]. Therefore, we may say that the irregularities of the host rim in $\mathrm{KC}$ patients did not result in higher astigmatism as compared to patients with FUCHS (regular host rim). However, SRI and SAI as defined by Wilson and Klyce [14] were significantly higher (which means unfavorable) in the FUCHS group before and after suture removal. Reasons for higher irregularity in FUCHS may include graft size, suture tension, wound adaptation, and tear film instability in older patients. An additional cause may be noncompliance to artificial tears.

Artificial tears are prescribed on a routine basis in our Department after PKP since we found that the incidence of immunologic graft rejections in non-high-risk keratoplasties is significantly increased in dry eye syndrome 
[15]. However, during follow-up only 4 mostly reversible immunological graft rejections (4.5\%) occurred in the present group of patients without a significant difference between FUCHS and KC [16]. Thus, differences in visual acuity between these two groups cannot be attributed to differences in corneal clouding.

Lin et al. [17] reported a significant decrease in the SAI value from 1.17 before to 0.93 after suture removal, indicating that surface asymmetries may decrease following the removal of a single running 10-0 nylon suture. In the $\mathrm{KC}$ group, we found somewhat favorable regularity values, but in FUCHS we found markedly higher values than those reported by Lin et al. [17]. Nevertheless, a tendency towards regularization after suture removal - as in the study by Lin et al. [17] - was documented in both groups. This suggests that also removal of a double running suture will increase the regularity of corneal topography and should be attempted clinically.

Recent studies have proven that there is no time point after PKP at which the 'good' topography of a graft would be resistant to changes after suture removal. This is true for PKP only and the triple procedure [18-20]. Unfortunately, at this time, no reliable indicator is available to the surgeon instructing him about the amount and direction of impending astigmatism or regularity changes of the graft after suture removal in an individual case.

In patients with KC, Tuft and Gregory [21] found that postoperative myopia largely resulted from abnormally elongated posterior segments rather than from corneal curvatures that are too steep. This is confirmed by the present study in which we found that the SEQ in the KC group was significantly more myopic than in FUCHS, especially before but also after suture removal. Nevertheless, before suture removal, this may in part be due to an increased tension of the double running sutures necessary for water-tight wound closure because of the thinner peripheral cornea in KC. The resulting 'purse string effect', a term coined by Assil et al. [22], effects central steepening of the cornea. This theory is well supported by the significantly higher central corneal power due to steeper grafts in KC with all sutures in, which diminished after suture removal. Nevertheless, results on the SEQ must be interpreted with care because of the uncertainty of IOL power calculation for the simultaneous cataract extraction [23].

We conclude that in $\mathrm{KC}$, keratometric astigmatism is not higher than in FUCHS during mid-term follow-up after PKP using excimer laser trephination. Long-term results may differ, e.g. due to KC progression in the recipient bed with biomechanical impact on the graft curvature. One of the reasons for inferior visual acuity in FUCHS may be the more irregular topography. After suture removal, graft topography in KC and FUCHS may be expected to regularize and the excessive corneal flattening in FUCHS to normalize.

\section{Acknowledgement}

Supported in part by the BMBF (IZKF Erlangen, Project B13) and Neurozentrum Erlangen, and the German Academic Exchange Service (grant No. 331403 003).

\section{References}

1 Meyer HJ, Cordesmeyer H: Zum postoperativen Astigmatismus nach Keratoplastik bei Keratokonus. Fortschr Ophthalmol 1987;84: 427-428.

2 Langenbucher A, Seitz B, Kus MM, Vilchis E, Naumann GO: Regularität der Topographie nach perforierender Keratoplastik Vergleich zwischen nichtmechanischer Trepanation (Excimer Laser 193nm) und mechanischer Trepanation. Klin Monatsbl Augenheilkd 1996;208:450-458.

3 Seitz B, Langenbucher A, Kus MM, Küchle M, Naumann GO: Nonmechanical corneal trephination with the excimer laser improves outcome after penetrating keratoplasty. Ophthalmology 1999;106:1156-1165.
4 Naumann GO, Seitz B, Lang GK, Langenbucher A, Kus MM: Excimer-Laser-193nm Trepanation bei der perforierenden Keratoplastik - Bericht über die ersten 70 Patienten. Klin Monatsbl Augenheilkd 1993;203:252261.

5 Naumann GOH: Corneal transplantation in anterior segment diseases. The Bowman lecture (number 56). II. Eye 1995;9:395-424.

6 Brahma A, Ennis F, Harper R, Ridgway A, Tullo A: Visual function after penetrating keratoplasty for keratoconus: a prospective longitudinal evaluation. Br J Ophthalmol 2000;84:60-66.

7 Lim L, Pesudovs K, Coster DJ: Penetrating keratoplasty for keratoconus: visual outcome and success. Ophthalmology 2000; 107:1125-1131.
8 Silbiger JS, Cohen EJ, Laibson PR: The rate of visual recovery after penetrating keratoplasty for keratoconus. CLAO J 1996;22:266269.

9 Young SR, Olson RJ: Results of a double running suture in penetrating keratoplasty performed on keratoconus patients. Ophthalmic Surg 1985;16:779-786.

10 Brierly SC, Izquierdo L Jr, Mannis MJ: Penetrating keratoplasty for keratoconus. Cornea 2000;19:329-332.

11 Pineros O, Cohen EJ, Rapuano CJ, Laibson PR: Long-term results after penetrating keratoplasty for Fuchs' endothelial dystrophy. Arch Ophthalmol 1996;114:15-18. 
12 Sautter H, Naumann GO, Demeler B: Über Erfahrungen mit gleichzeitiger perforierender Keratoplastik und Kataraktextraktion. Klin Monatsbl Augenheilkd 1973;163:290298.

13 Seitz B, Langenbucher A, Küchle M, Naumann GO: Impact of graft diameter on corneal power and the regularity of postkeratoplasty astigmatism before and after suture removal. Ophthalmology 2003;110:21622167.

14 Wilson SE, Klyce SD: Quantitative descriptors of corneal topography: a clinical study. Arch Ophthalmol 1991;109:349-353.

15 Küchle M, Cursiefen C, Nguyen NX, Langenbucher A, Seitz B, Wenkel H, Martus P, Naumann GO: Risk factors of corneal allograft rejection: intermediate results of a prospective normal-risk keratoplasty study. Graefes Arch Clin Exp Ophthalmol 2002; 240:580-584.
16 Seitz B, Langenbucher A, Diamantis A, Cursiefen C, Küchle M, Naumann GO: Immunreaktionen nach perforierender Keratoplastik - eine prospektive randomisierte Vergleichstudie zwischen Excimerlaser- und Motortrepanation. Klin Monatsbl Augenheilkd 2001;218:710-719.

17 Lin DT, Wilson SE, Reidy JJ, Klyce SD, McDonald MB, Insler MS, Kaufman HE: Topographic changes that occur with 10-0 running suture removal following penetrating keratoplasty. Refract Corneal Surg 1990;6: 21-25.

18 Davis EA, Azar DT, Jakobs FM, Stark WJ: Refractive and keratometric results after the triple procedure. Experiences with early and late suture removal. Ophthalmology 1998; 105:624-630.

19 Filatov V, Alexandrakis G, Talamo JH, Steinert RF: Comparison of suture-in and sutureout postkeratoplasty astigmatism with single running suture or combined running and interrupted sutures. Am J Ophthalmol 1996; 122:696-700.
20 Mader TH, Yaun R, Lynn MJ, Stulting RD, Wilson LA, Waring GO 3rd: Changes in keratometric astigmatism after suture removal more than one year after penetrating keratoplasty. Ophthalmology 1993;100:119-127.

21 Tuft SJ, Gregory W: Long-term refraction and keratometry after penetrating keratoplasty for keratoconus. Cornea 1995;14:614617.

22 Assil KK, Zarnegar SR, Schanzlin DJ: Visual outcome after penetrating keratoplasty with double continuous or combined interrupted and continuous sutures for wound closure. Am J Ophthalmol 1992;114:63-71.

23 Seitz B, Langenbucher A, Viestenz A, Dietrich T, Küchle M, Naumann GO: Katarakt und Keratoplastik - simultane oder sequenzielle Operation? Klin Monatsbl Augenheilkd 2003;220:326-329. 